\title{
Single dose pharmacokinetic equivalence study of two gabapentin preparations in healthy subjects
}

This article was published in the following Dove Press journal:

Drug Design, Development and Therapy

4 September 2014

Number of times this article has been viewed

\author{
Raymond R Tjandrawinata \\ Effi Setiawati ${ }^{2}$ \\ Ratih Sofia Ika Putri \\ Danang Agung Yunaidi ${ }^{2}$ \\ Fawzia Amalia ${ }^{2}$ \\ Liana W Susanto'
}

'Dexa Laboratories of Biomolecular Sciences, Cikarang, Indonesia; ${ }^{2}$ PT Equilab International, Bioavailability and Bioequivalence Laboratory, Jakarta, Indonesia
Correspondence: Raymond R

Tjandrawinata

Dexa Laboratories of Biomolecular

Sciences, Dexa Medica Group, Indonesia, Industri Selatan V, Block PP no 7,

Kawasan Industri Jababeka II, Cikarang

17550, Indonesia

Tel +62218984 190।

Fax +622189841905

Email raymond@dexa-medica.com
Background: The current study was conducted to find out whether two oral preparations of $300 \mathrm{mg}$ gabapentin (the test and reference capsules) were bioequivalent.

Subjects and methods: This was a randomized, single-blind, crossover study under fasting condition, with a 7-day washout period, which included 37 healthy adult male and female subjects. After an overnight fast, subjects were given, orally, one capsule of the test drug or of the reference drug. Blood samples were drawn immediately before taking the drug, then at 20 and 40 minutes, and 1, 1.5, 2, 2.5, 3, 4, 5, 6, 8, 10, 12, 15, and 24 hours after dosing, to evaluate pharmacokinetic parameters of the single dose administration, ie, the area under the plasma concentration-time curve (AUC) from time zero to 24 hours $\left(\mathrm{AUC}_{\mathrm{t}}\right), \mathrm{AUC}$ from time zero to infinity $\left(\mathrm{AUC}_{\mathrm{inf}}\right)$, the peak plasma concentration of the drug $\left(\mathrm{C}_{\max }\right)$, time needed to achieve $\mathrm{C}_{\max }\left(\mathrm{t}_{\max }\right)$, and the elimination half-life $\left(\mathrm{t}_{1 / 2}\right)$. The plasma concentrations of gabapentin were determined using validated high-performance liquid chromatography with ultraviolet detection.

Results: The geometric mean ratios ( $90 \%$ confidence interval) of the test drug/reference drug for gabapentin were 103.15\% (90.38\%-117.72\%) for $\mathrm{AUC}_{\mathrm{t}}, 103.53 \%(90.78 \%-118.07 \%)$ for $\mathrm{AUC}_{\mathrm{inf}}$, and $108.06 \%(96.32 \%-121.24 \%)$ for $\mathrm{C}_{\max }$. The differences in $\mathrm{t}_{\max }$ and $\mathrm{t}_{1 / 2}$ values between the test and reference drug products for gabapentin were not statistically significant. Light-headedness, nausea, and headache were encountered during the study, but they were all mild and well tolerated. The $90 \%$ confidence intervals of the test/reference AUC ratio and $\mathrm{C}_{\max }$ ratio of gabapentin were within the acceptance range for bioequivalence.

Conclusion: The two preparations of gabapentin $300 \mathrm{mg}$ capsule were bioequivalent, thus both can be used interchangeably in the clinical setting.

Keywords: bioavailability, bioequivalence, antiepilepsy, bioavailability, bioequivalence

\section{Introduction}

Gabapentin is an antiepileptic drug effective in the treatment of partial seizures, with or without secondary generalization, and is used as either a monotherapy or an adjunctive therapy to other antiepileptic drugs, with the usual therapeutic dose ranges from $300 \mathrm{mg}$ up to $1.2 \mathrm{~g}$, three times daily (TID). It is not generally considered effective for absence seizures. Although gabapentin is an analogue of gamma-aminobutyric acid (GABA), it is neither a GABA agonist nor antagonist, and its mechanism of action is unknown. ${ }^{1-4}$ Gabapentin is also used in the treatment of neuropathic pain, with the usual dose being 300 to $600 \mathrm{mg}$ TID. ${ }^{1,5-10}$

Gabapentin $\left(\mathrm{C}_{9} \mathrm{H}_{17} \mathrm{NO}_{2}\right)$ is chemically described as 1-(aminomethyl) cyclohexane acetic acid, with a molecular weight of 171.24. Gabapentin is a white to off-white crystalline solid, freely soluble in water and, in both alkaline and acidic aqueous solutions. ${ }^{1}$

Following oral administration, gabapentin is absorbed from the gastrointestinal tract through a saturable transport mechanism. Consequently, gabapentin 
bioavailability decreases as the dose increases. Within the recommended dose range of 300 to $600 \mathrm{mg}$ TID, however, the differences in bioavailability are relatively small, with the bioavailability of about $60 \% .^{2,11}$ Food has only a slight effect on the rate and extent of absorption of gabapentin, but dietary proteins may favorably influence those parameters significantly. ${ }^{12}$ After a single dose of $400 \mathrm{mg}$ gabapentin, the peak plasma concentration $\left(\mathrm{C}_{\max }\right)$ is expected to be about $5.5 \mu \mathrm{g} / \mathrm{mL}$, with the time needed to achieve $\mathrm{C}_{\text {max }}\left(\mathrm{t}_{\max }\right)$ being about 2-3 hours after administration. Less than 3\% of circulating gabapentin is bound to plasma protein. Gabapentin is not appreciably metabolized in humans and is eliminated by renal excretion as unchanged drug. Its elimination half-life $\left(t_{1 / 2}\right)$ is 5 to 9 hours and is unaltered by dose size or following multiple dosing. The gabapentin elimination rate constant, and plasma and renal clearance, are directly proportional to the creatinine clearance, thus the dose is adjusted based on renal function. ${ }^{2,11}$

The most common adverse effects observed with gabapentin in adults are somnolence, dizziness, ataxia, and fatigue. These effects are usually mild to moderate in severity and resolve within 2 weeks of the onset during continued treatment. Overall, gabapentin is well tolerated. ${ }^{5}$

The present study compared the pharmacokinetics of two different oral gabapentin preparations given in capsule dosage form, following single dosing in healthy adult subjects, in order to prove that both preparations are bioequivalent. A drug is considered bioequivalent to the reference drug when the under the plasma concentration-time curve (AUC) and the $\mathrm{C}_{\max }$ of the drug are within $80 \%-125 \%$ of the AUC and $\mathrm{C}_{\max }$ of the reference drug, respectively. ${ }^{13-16}$

\section{Materials and methods Study design}

This was a randomized, single-blind, crossover study under fasting condition, with a 7-day washout period, involving 37 healthy adults. Subject screening, to assess the eligibility, was carried out within 2 weeks prior to their first dosing day and included vital signs (blood pressure, heart rate, respiratory rate, and body temperature), physical examination, electrocardiography (ECG), and laboratory exams for liver function (alanine transaminase (ALT), aspartate transaminase (AST), alkaline phosphatase, and total bilirubin), renal function (serum creatinine and urea), hematology (hemoglobin, leucocyte, and platelet count), blood glucose, routine urinalysis $(\mathrm{pH}$, glucose, protein, and urine sediment), and seroimmunology (hepatitis B surface antigen [HBsAg], hepatitis C antibody [anti-HCV], and human immunodeficiency virus antibody [anti-HIV]). A pregnancy test (for women) was performed just before taking the drug in each period.

The inclusion criteria were healthy male or female subjects aged between 18-55 years at screening, body mass index (BMI) between 18 and $25 \mathrm{~kg} / \mathrm{m}^{2}$, and had signed the informed consent. The exclusion criteria were: pregnancy or lactating mothers; known contraindication or hypersensitivity to gabapentin; liver dysfunction (defined as ALT, alkaline phosphatase; or total bilirubin level of $1.5 \times$ upper limit of normal); renal insufficiency (defined as serum creatinine level above $1.4 \mathrm{mg} / \mathrm{dL}$ ); abnormal hematology with clinical significance; positive test results for $\mathrm{HBsAg}$, anti-HCV, and/ or anti-HIV; any medical condition that might significantly alter the absorption, distribution, metabolism or excretion of the study drug, such as gastrointestinal diseases or history of gastric surgery; history of anaphylaxis or angioedema, seizure, epilepsy or any kind of neurological disorders; any bleeding or coagulation disorders; drug or alcohol abuse; or intake of any prescription or nonprescription drugs, food supplements, or herbal medicines within 14 days of the first dosing day.

The eligibility criteria in this study were set to ensure that only a healthy subject population, without accompanying diseases that would interfere with the conduct and scientific evaluation of the study, were enrolled in the study. Additionally, involving only healthy subjects would minimize risk to the subject's well-being.

The test preparation (gabapentin $300 \mathrm{mg}$ capsules, batch number 4208195) was manufactured in plant site Palembang (PT Dexa Medica, Palembang, Indonesia). The reference preparation, Neurontin ${ }^{\circledR}$ capsules (batch number 0615080; Pfizer Deutschland GmbH, Berlin, Germany), each containing gabapentin $300 \mathrm{mg}$, was the innovator's product and was purchased from the local pharmacy.

\section{Clinical conduct}

The study was carried out in compliance with the Declaration of Helsinki, ${ }^{17}$ Good Clinical Practice, ${ }^{18}$ and Good Laboratory Practice. ${ }^{19}$ The protocol, the patient information, and consent form were reviewed and approved by the independent Ethics Committee of the Medical Faculty, University of Indonesia, prior to the study conduct.

Subjects attended the study site the night before drug administration, and they were requested to be fasting, avoiding any food and drink except mineral water. Foods, especially those containing high levels of proteins, have a sizeable effect on the rate and extent of absorption of gabapentin, with a contribution of about $26 \%$ increase to the AUC 
and $32 \%$ to the $\mathrm{C}_{\max }{ }^{12}$ Gabapentin $300 \mathrm{mg}$ capsules, in this study, were administered to subjects right after an overnight fast in order to eliminate that pharmacokinetic interactions between food and drug, including the influence of food on drug absorption. In the morning (after a 10-hour fast), a predose blood sample was taken. Immediately afterwards, the study drug (one capsule of the test drug or the reference drug) was given with $200 \mathrm{~mL}$ of water. The date and the time of taking each sample were recorded. The single-blind procedure was performed by giving the drug in a closed opaque bottle prepared by an independent person so that the investigator could not recognize the allocation of study subjects (investigator-blind). The analyst in the laboratory was also blinded to the randomization code until the code was disclosed just before statistical analysis.

Next meals were provided 4 hours and 10 hours after the dosing. The amounts of food and water intake as well as physical activity for each individual subject were standardized during the sampling days. Subjects were not allowed to take xanthine-containing food or beverages or fruit juices for 24 hours before and during the entire sampling days. From each subject, venous blood samples were drawn: $10 \mathrm{~mL}$ immediately before taking the drug (control) and $5 \mathrm{~mL}$ each at 20 and 40 minutes and at 1, 1.5, 2, 2.5, 3, 4, 5, 6, 8, $10,12,15$, and 24 hours. Seven days after the first dosing (ie, washout period), the same procedure was repeated with the alternate drug. Blood samples were drawn using a $22 \mathrm{G}$ needle and citrate vacuum tubes, or by disposable syringe if the vacuum tube was blocked. The blood samples collected from all subjects at each time point were centrifuged at 4,000 rpm for 15 minutes to separate the plasma, which was then transferred to a clean tube. All plasma samples were stored in a freezer at $-20^{\circ} \mathrm{C} \pm 5^{\circ} \mathrm{C}$, until assayed. The date and time of taking each sample were recorded in the case report forms.

\section{Analytical conduct}

\section{Analytical method and validation}

The plasma concentrations of gabapentin were assayed using thoroughly validated high-performance liquid chromatography with ultraviolet detector (HPLC-UV) (Alliance ${ }^{\mathrm{TM}}$, Waters Corp, Milford, MA, USA), with adequate sensitivity, specificity, linearity, recovery, accuracy, and precision, both within and between days. The following validation data were taken from our validation report.

The standard calibration curve of gabapentin ranged from 50.10 to $6,011.98 \mathrm{ng} / \mathrm{mL}$. The linear relationship between concentration and signal intensity was obtained, with a correlation coefficient that ranged from $r=1.0000$ to $r=1.0000$ in three different runs on at least 2 different days. The lower limit of quantitation (LLOQ) of this study was $50.03 \mathrm{ng} / \mathrm{mL}$. The intra-assay precision data, expressed as coefficient of variation (CV) were $2.42 \%, 7.38 \%, 5.68 \%$, and $1.97 \%$, at LLOQ (50.03 ng/mL), low (150.10 ng/mL), medium $(750.52 \mathrm{ng} / \mathrm{mL})$, and high $(4,503.14 \mathrm{ng} / \mathrm{mL})$ concentrations, respectively, and interassay CVs were $6.13 \%$, $6.25 \%, 3.65 \%$, and $1.69 \%$ at LLOQ, low, medium, and high concentrations, respectively. The intra-assay accuracy data, expressed as \% difference from the actual value, were: $-2.06 \%, 1.78 \%,-0.87 \%$, and $1.78 \%$ at LLOQ, low, medium, and high concentrations, respectively, and interassay data were $-0.82 \%,-0.41 \%,-1.41 \%$, and $2.11 \%$ at LLOQ, low, medium, and high concentrations, respectively.

In terms of selectivity, the chromatograms showed there were no interfering substances in six blank plasma samples. The recovery, expressed as \% of the standard recovered in blank plasma compared with the actual values, were $107.65 \%, 103.27 \%$, and $89.19 \%$, for the low, medium, and high concentrations, respectively.

Stability of the samples, at room temperature, under frozen storage conditions $\left(-20^{\circ} \mathrm{C}\right)$, and postpreparation (during in the autosampler condition of the chromatographic system), were also determined. Gabapentin was stable in the plasma samples at room temperature for 4 hours, with $\%$ difference from the actual value that ranged from $-13.71 \%$ to $-10.16 \%$ for the low concentration and $-10.47 \%$ to $-5.34 \%$ for the high concentration. At $-20^{\circ} \mathrm{C}$, the drug was stable in plasma samples for 144 days, with \% difference from the actual value that ranged from $-6.04 \%$ to $+1.55 \%$ and from $-8.68 \%$ to $+8.29 \%$ for the low and high concentrations, respectively. Postpreparation, the samples were stable in the autosampler condition for 187 hours, with $\%$ difference from the actual value that ranged from $0.01 \%$ to $4.17 \%$, from $0.12 \%$ to $2.80 \%$, and from $-1.17 \%$ to $+2.93 \%$, for the low, medium, and high concentrations, respectively.

\section{Assay procedure}

The procedures described were applied for the extraction of subject samples, calibration, and quality control standards. Calibration standards, controls, and samples were processed in batches. Each plasma sample was dispensed in an appropriate tube, and then the baclofen internal standard solution and methanol, as the organic solvent, were added. The content of the tube was vortexed and centrifuged. The organic phase was transferred to a vial, evaporated to dryness at $50^{\circ} \mathrm{C}$ 
under a nitrogen stream. The residue was reconstituted with acetonitrile:water (2:7), vortexed, and then injected into the HPLC-UV system, with a suitable condition, as detailed below.

The analytical column used was the Sunfire ${ }^{\mathrm{TM}}$ Column C18 $5 \mu \mathrm{m}, 4.6 \times 150 \mathrm{~mm}$; while the guard-column was a Symmetry $^{\mathrm{TM}} \mathrm{C} 185 \mu \mathrm{m}, 3.9 \times 20 \mathrm{~mm}$. Column temperature was set at $45^{\circ} \mathrm{C}$. The mobile phase was an acetonitrile:acetate buffer:methanol (28:50:22) solution, set at a flow rate of $1.2 \mathrm{~mL} / \mathrm{min}$. The UV detector was used at a wavelength of $240 \mathrm{~nm}$. The instrument automatically injected $50 \mu \mathrm{L}$ samples into the chromatographic system.

All chromatograms in the same batch were processed automatically with software using the same processing parameters, such as integration, peak-to-peak amplitude, and peak detection. Manual integration was performed only when necessary.

\section{Pharmacokinetic evaluation}

The pharmacokinetic parameters of gabapentin were determined by employing noncompartmental pharmacokinetic analysis. $\mathrm{C}_{\max }(\mathrm{ng} / \mathrm{mL})$ and $\mathrm{t}_{\max }$ (hours) were generated directly from the current study. The AUC from time zero to the last measurable concentration time $\left(\mathrm{AUC}_{\mathrm{t}}\right)$ was calculated by the trapezoidal method. The AUC from time zero extrapolated to infinite time $\left(\mathrm{AUC}_{\mathrm{inf}}\right)$ was calculated according to the formula:

$$
\mathrm{AUC}_{\mathrm{inf}}=\mathrm{AUC}_{\mathrm{t}}+\mathrm{C}_{\mathrm{t}} / \mathrm{k}_{\mathrm{e}}
$$

where $\mathrm{C}_{\mathrm{t}}$ is the last quantifiable concentration and $\mathrm{k}_{\mathrm{e}}$ is the terminal elimination rate constant, determined by leastsquares regression analysis during the terminal log-linear phase of the concentration-time curve. The $t_{1 / 2}$ (hours) was calculated according to the formula:

$$
\mathrm{t}_{1 / 2}=0.693 / \mathrm{k}_{\mathrm{e}}
$$

\section{Statistical analysis}

Analysis of variance (ANOVA) (SPSS for Windows Version 14; SPSS Inc., Chicago, IL, USA) was used to perform the statistical analyses of $\mathrm{AUC}_{\mathrm{t}}, \mathrm{AUC}_{\mathrm{inf}}$, and $\mathrm{C}_{\max }$, after transformation of the data to their logarithmic (ln) values. The $90 \%$ confidence intervals (CIs) were calculated from the following equation:

$$
90 \% \mathrm{CI}=\left(\bar{X}_{\mathrm{T}}-\bar{X}_{\mathrm{R}}\right) \pm \mathrm{t}_{0.1(\mathrm{v})} \sqrt{s^{2} \times\left(\frac{1}{n_{R T}}+\frac{1}{n_{T R}}\right)}
$$

where $\bar{X}_{\mathrm{T}}$ and $\bar{X}_{\mathrm{R}}$ are the means of the ln-transformed values for the test product (T) and the reference product (R), $S^{2}$ is the error variance obtained from the ANOVA, $n$ is the number of subjects; $\mathrm{t}_{0.1}$ is the $t$-value for $90 \% \mathrm{CI}, \mathrm{v}$ is the degree of freedom of the error variance from the ANOVA, $n_{R T}$ is the number of subjects (sequence $R T$ ), and $n_{T R}$ is the number of subjects (sequence $T R$ ).

The anti-ln of the above CIs were the $90 \% \mathrm{Cls}$ of the ratios of the test/reference geometric means. The power of study was $80 \%$ with 0.05 alpha $(\alpha)$.

The acceptance criteria for bioequivalence were that the $90 \% \mathrm{Cls}$ of the geometric mean ratios were $0.80-1.25$ for the AUC and $\mathrm{C}_{\max }$. The $\mathrm{t}_{\max }$ difference was analyzed nonparametrically on the original data, using the Wilcoxon signedrank test. The $t_{1 / 2}$ difference was analyzed using Student's paired $t$-test or Wilcoxon signed-rank test, depending on the distribution of the paired-data.

\section{Results}

A total of 37 subjects (24 male and 13 female) aged 19-54 years old, with BMIs between 18.03 and $24.99 \mathrm{~kg} / \mathrm{m}^{2}$, were enrolled in this study. All of them were healthy Indonesian subjects, had normal clinical as well as laboratory values measured, and met the inclusion/exclusion criteria of the study. Blood samples pertaining to each study subject in each study period were analyzed for pharmacokinetic evaluation of gabapentin.

The profiles of mean plasma concentrations versus time in subjects $(n=37)$, after a single oral administration of gabapentin $(300 \mathrm{mg})$ capsules of the test drug and reference drug under fasting condition, are presented in Figure 1. The values for the pharmacokinetic parameters ( $\mathrm{AUC}_{\mathrm{t}}, \mathrm{AUC}_{\mathrm{inf}}$, $\mathrm{C}_{\max }, \mathrm{t}_{1 / 2}$, and $\left.\mathrm{t}_{\max }\right)$ and the geometric mean ratios $(90 \% \mathrm{CI})$

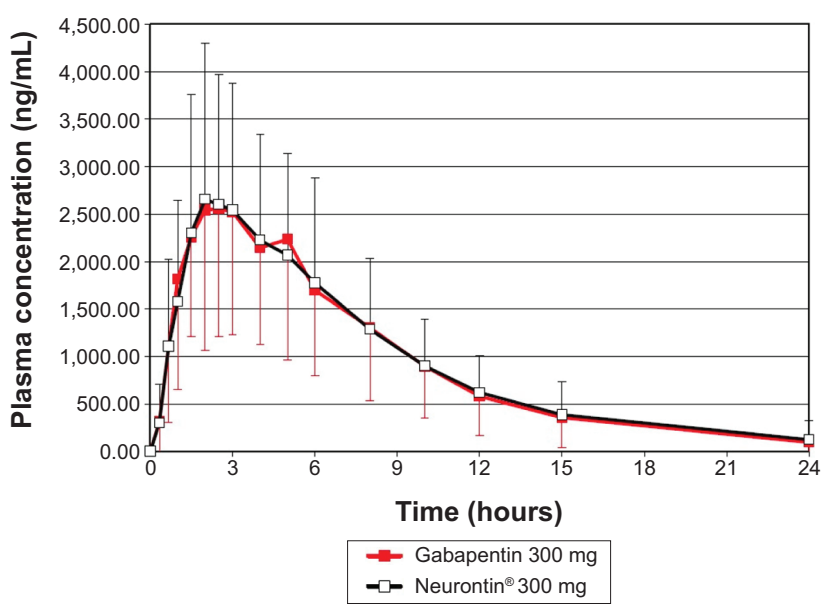

Figure I Mean plasma concentrations versus time profiles of gabapentin in human subjects $(n=37)$ after a single-dose oral administration of $300 \mathrm{mg}$ gabapentin capsules of the test drug and the reference drug. 
Table I Pharmacokinetic parameters and statistical comparison of gabapentin after a single oral administration of gabapentin $300 \mathrm{mg}$ capsule of the test drug and the reference

\begin{tabular}{|c|c|c|c|c|}
\hline Parameter & $\begin{array}{l}\text { Test product } \\
\text { mean (SD) }\end{array}$ & $\begin{array}{l}\text { Reference } \\
\text { mean (SD) }\end{array}$ & $\begin{array}{l}\text { Geometric mean ratio } \\
\text { of } T / R(90 \% \mathrm{Cl})\end{array}$ & $\% \mathbf{C V}$ \\
\hline $\mathrm{AUC}_{\mathrm{t}}\left(\mathrm{ng} \cdot \mathrm{h} \cdot \mathrm{mL}^{-1}\right)$ & $21,734.09(10,174.13)$ & $22,099.11$ (10,547.72) & $103.15 \%(90.38 \%-117.72 \%)$ & $33.64 \%$ \\
\hline$A \cup C_{\text {inf }}\left(\mathrm{ng} \cdot \mathrm{h} \cdot \mathrm{mL}^{-1}\right)$ & $23,260.86(10,67 \mid .42)$ & $23,574.03(11,501.55)$ & $103.53 \%(90.78 \%-118.07 \%)$ & $33.46 \%$ \\
\hline $\mathrm{C}_{\max }\left(\mathrm{ng} \cdot \mathrm{mL}^{-1}\right)$ & $3,289.63(1,404.56)$ & $3,223.69(1,606.03)$ & $108.06 \%(96.32 \%-121.24 \%)$ & $29.28 \%$ \\
\hline$t_{1 / 2}(h)$ & $4.92(1.95)$ & $4.69(1.79)$ & $N S^{b}$ & \\
\hline$t_{\max }(h)^{a}$ & $2.50(1.00-6.00)$ & $2.50(1.50-8.00)$ & $N S^{c}$ & \\
\hline
\end{tabular}

Notes: ${ }^{V}$ Values are expressed as median (range). ${ }^{b}$ Analysis was performed by Wilcoxon matched-pair test; canalysis was performed by Student's paired $t$-test. Statistical calculations for AUC and $C_{\max }$ were based on In-transformed data. Bioequivalence criteria are defined as $90 \% \mathrm{Cl}$ of the geometric mean ratios of T/R of $80.0 \%-125.0 \%$ for $A \cup C_{t}, A \cup C_{i n f}$ and $C_{m a x}$

Abbreviations: $A \cup C$, area under the plasma concentration-time curve; $A \cup C_{\text {inf }}$ AUC from time zero to infinity; $A \cup C_{t}$, $A \cup C$ from time zero to 24 hours; $C_{\text {max }}$, peak plasma concentration of the drug; $\mathrm{Cl}$, confidence interval; $\mathrm{CV}$, within-subject variability; NS, not statistically significant; $\mathrm{R}$, reference drug; SD, standard deviation; $\mathrm{T}$, test drug; $\mathrm{t}_{1 / 2}$, elimination half-life; $\mathrm{t}_{\max }$, time needed to achieve $\mathrm{C}_{\max }$.

of $\mathrm{AUC}_{\mathrm{t}}, \mathrm{AUC}_{\mathrm{inf}}$, and $\mathrm{C}_{\max }$ of gabapentin for the test drug as well as the reference drug are presented in Table 1.

\section{Discussion}

The aim of the present study was to evaluate whether the test preparation of gabapentin $300 \mathrm{mg}$ capsules had pharmacokinetic equivalence (or was bioequivalent) to the reference preparation. When the test product (the so-called generic product) with the same active substance, strength, and route of administration (pharmaceutical equivalence) as the reference product (usually, the Innovator's product) is proven bioequivalent to the reference by scientifically sound evidence, that generic product is considered therapeutic equivalent to the reference, thus both can be used interchangeably. ${ }^{16}$ Providing bioequivalent generic products is unavoidably necessary, both in developing and developed countries, because the products are certainly more affordable than the reference. Particularly for products that will be used for a long period, the availability of bioequivalent generics will definitely help the patients. With respect to antiepileptic drugs, the highest levels of evidence indicated that generic substitution would not be problematic, although some patients were more prone to problems with the generic products. $^{20}$

The test preparation of gabapentin evaluated in this study was of a different formulation and manufacturer than those evaluated in previous similar publications of gabapentin bioequivalence. ${ }^{21-24}$ Moreover, our study evaluated the bioavailability of a lower dose of gabapentin preparation (300 mg capsule) than those in former similar studies (400 mg to $800 \mathrm{mg}$ capsules). ${ }^{22-24}$

The selection of HPLC/UV-detector as the method to determine gabapentin concentrations in human plasma was based on previous studies..$^{25,26}$ The HPLC-UV is a sensitive method with excellent sensitivity and reproducibility for application in bioequivalence studies of gabapentin, ${ }^{25,26}$ as was also demonstrated in our own validation data. Other former bioequivalence studies with different gabapentin formulations conducted by Wittayalertpanya et al, ${ }^{21}$ Cho et $\mathrm{al}^{22}$ and Almeida et $\mathrm{al}^{23}$ also used the HPLC method, but with fluorescence ${ }^{21,22}$ or mass spectrometry (MS) detector, ${ }^{23}$ instead of UV detector as used in our study. In this study, UV detector was preferred to fluorescence or to MS detector because the level of gabapentin in human plasma is sufficient for detection by UV detector. Moreover, this detector is more commonly available in a laboratory and much less expensive than the fluorescence and MS detectors. ${ }^{27,28}$

The number of subjects needed for a bioequivalence study with bioequivalence limits of 0.80 and 1.25 for AUC and $\mathrm{C}_{\max }$ was determined by means of $\mathrm{Cis}$, as formerly presented by Diletti et al. ${ }^{29}$ The intrasubject $\% \mathrm{CV}$ obtained in the study for gabapentin $\mathrm{AUC}_{\mathrm{t}}$ was $33.64 \%$ (Table 1). To fulfil the requirement for $80 \%$ statistical power for this study, a minimum number of 36 subjects were needed. Therefore the study result could reliably be concluded based on data of the enrolled 37 subjects. The intrasubject CV expresses the variability of gabapentin absorption between different formulations in the same given individual. Other similar study by Wittayalertpanya et $\mathrm{al}^{21}$ in which gabapentin $300 \mathrm{mg}$ capsules were also used but which used HPLC-fluorescence instead of HPLC-UV, involved a lesser number of subjects ( 24 subjects). However, the paper did not report the intrasubject $\mathrm{CV}$ of the $\mathrm{AUC}_{\mathrm{t}}$; therefore, we can not discuss further whether the different detector they used resulted in smaller intrasubject $\mathrm{CV}$, thus requiring a lesser number of subjects. 
In this study, the $\mathrm{AUC}_{\mathrm{t}}, \mathrm{AUC}_{\mathrm{inf}}$, and $\mathrm{C}_{\max }$ of gabapentin were defined as the main parameters in order to assess possible bioequivalence between both preparations. Based on standard bioequivalence guidelines, the criteria for bioequivalence are the $90 \% \mathrm{CI}$ of the test/reference geometric means ratio that falls in the range of 80.00 to $125.00 \%$ for both $\mathrm{AUC}$ and $\mathrm{C}_{\max }{ }^{13-16}$ This criteria for assessing the bioequivalence of generic products assures that the substitute product does not deviate substantially in in vivo performance from the reference product. ${ }^{29}$ The results of the present study showed that the geometric mean ratios $(90 \% \mathrm{CI})$ of $\mathrm{AUC}_{\mathrm{t}}, \mathrm{AUC}_{\mathrm{inf}}$, and $\mathrm{C}_{\max }$ of gabapentin were 103.15\% (90.38\%-117.72\%), 103.53\% (90.78\%-118.07\%), and 108.06\% (96.32\%-121.24\%), respectively. The $90 \% \mathrm{CIs}$ of the test/reference ratios for $\mathrm{AUC}_{\mathrm{t}}, \mathrm{AUC}_{\mathrm{inf}}$, and $\mathrm{C}_{\max }$ of gabapentin were within the acceptance range for bioequivalence.

In each subject, the $\mathrm{AUC}_{\mathrm{t}} / \mathrm{AUC}_{\text {inf }}$ ratio of gabapentin was above $80 \%(81.00 \%$ to $99.17 \%$ for the test drug and $83.43 \%$ to $98.91 \%$ for the reference drug), indicating that the sampling time was sufficiently long to ensure an adequate description of the absorption phase.

The mean (standard deviation) $t_{1 / 2}$ of gabapentin for the test drug was 4.92 (1.95) hours and for the reference drug was 4.69 (1.79) hours, which were not different from that in the literature (about 5 to 9 hours). ${ }^{2,11}$ Utilizing the Student's paired $t$-test, the $\mathrm{t}_{1 / 2}$ values of the test and the reference drug were not significantly different, demonstrating a comparable rate of drug elimination from the body.

The median (range) $\mathrm{t}_{\max }$ of the test drug was 2.50 (1.00-6.00) hours and $2.50(1.50-8.00)$ hours for the reference drug, which were also in alignment with that in the literature (2-3 hours). ${ }^{1,2}$ Using Wilcoxon matched-pairs test on the original data, the difference between the $t_{\max }$ values of the two drugs (test and reference drug) was not statistically significant.

There were three adverse events, reporting lightheadedness, nausea, and headache, encountered during the study. Lightheadedness occurred in eight subjects during first period and in four subjects during second period, while nausea and headache occurred in one subject during first period. However, those adverse events were all mild and well tolerated by study subjects, thus caused no subjects to drop out from the study.

\section{Conclusion}

Based on the pharmacokinetics results of this study, it was concluded that the two preparations of gabapentin $300 \mathrm{mg}$ capsule were bioequivalent; thus both can be used interchangeably in the clinical setting.

\section{Acknowledgment}

We deeply thank the volunteers for their participation in this study.

\section{Disclosure}

The authors report no conflicts of interests in this work.

\section{References}

1. Sweetman SC, editor. Martindale: The Complete Drug Reference. 36th ed. New York, NY: The Pharmaceutical Press; 2009:482-484.

2. Berry DJ, Beran RG, Plunkeft MJ, Clarke LA, Hung WT. The absorption of gabapentin following high dose escalation. Seizure. 2003; 12(1):28-36.

3. Browne TR. Efficacy and safety of gabapentin. In: Chadwick D, editor. New Trends in Epilepsy Management: The Role of Gabapentin. London: Royal Society of Medicine Services Ltd; 1993:41-46.

4. Chadwick D. The role of gabapentin in epilepsy management. In: Chadwick D, editor. New Trends in Epilepsy Management: The Role of Gabapentin. London: Royal Society of Medicine Services Ltd; 1993: 59-65.

5. Rose MA, Kam PC. Gabapentin: pharmacology and its use in pain management. Anaesthesia. 2002;57(5):451-462.

6. Backonja M, Glanzman RL. Gabapentin dosing for neuropathic pain: evidence from randomized, placebo-controlled clinical trials. Clin Ther. 2003;25(1):81-104.

7. Singh D, Kennedy DH. The use of gabapentin for the treatment of postherpetic neuralgia. Clin Ther. 2003;25(3):852-889.

8. Backonja M, Beydoun A, Edwards KR, et al. Gabapentin for the symptomatic treatment of painful neuropathy in patients with diabetes mellitus: a randomized controlled trial. JAMA. 1998;280(21):1831-1836.

9. Morello CM, Leckband SG, Stoner CP, Moorhouse DF, Sahagian GA. Randomized double-blind study comparing the efficacy of gabapentin with amitriptyline on diabetic peripheral neuropathy pain. Arch Intern Med. 1999;159(16):1931-1937.

10. Banerjee M, Pal S, Bhattacharya B, Ghosh B, Mondal S, Basu J. A comparative study of efficacy and safety of gabapentin versus amitriptyline as coanalgesics in patients receiving opioid analgesics for neuropathic pain in malignancy. Indian J Pharmacol. 2013;45(4):334-338.

11. McLean MJ. Clinical pharmacokinetics of gabapentin. Neurology. 1994;44(6 Suppl 5):S17-S22; discussion S31-S32.

12. Gidal BE, Maly MM, Kowalski JW, Rutecki PA, Pitterle ME, Cook DE. Gabapentin absorption: effect of mixing with foods of varying macronutrient composition. Ann Pharmacother. 1998;32(4):405-409.

13. Committee for Medicinal Products for Human Use (CHMP), European Medicines Agency (EMA). Guideline on the Investigation of Bioequivalence. Rev 1. London: European Medicines Agency; 2010. Available from: http://www.ema.europa.eu/docs/en_GB/document_library/ Scientific_guideline/2010/01/WC500070039.pdf. Accessed August 28, 2014.

14. Badan Pengawas Obat dan Makanan Republik Indonesia (BPOM RI). Pedoman Uji Bioekuivalensi. [Indonesian Guideline for Bioequivalence Studies]. Jakarta: BPOM; 2004. Available from http://jdih.pom.go.id/ showpdf.php? $\mathrm{u}=89$. Accessed August 28, 2014. Indonesian.

15. Badan Pengawas Obat dan Makanan Republik Indonesia (BPOM RI). Peraturan Kepala BPOM RI Nomor. HK.03.1.23.12.11.10217. Tahun 2011. Tentang Obat Wajib Uji Bioequivalensi [BPOM-RI Regulation for Drugs Compulsory for Bioequivalence Studies]. Jakarta: BPOM; 2011. Available from http://jdih.pom.go.id/showpdf.php?u=97. Accessed August 28, 2014. Indonesian. 
16. fda.gov [homepage on the Internet]. Orange book preface Approved drug products with therapeutic equivalence evaluations. 34th ed. Food and Drug Administration; 2014 [updated March 14, 2014; cited June 12, 2014]. Available from: http://www.fda.gov/drugs/development approvalprocess/ucm079068.htm Accessed August 4, 2014.

17. 52nd World Medical Association General Assembly. Declaration of Helsinki. Recommendations Guiding Physicians in Biomedical Research Involving Human Patients. Edinburgh: World Medical Association; 2000.

18. International Conference on Harmonisation (ICH) Expert Working Group. ICH Harmonised Tripartite Guideline. Guideline for Good Clinical Practice E6(R1). Geneva: International Conference on Harmonisation of Technical Requirements for Registration of Pharmaceuticals for Human Use; 1996.

19. Organization for Economic Co-operation and Development (OECD). OECD Series on Principles of Good Laboratory Practice and Compliance Monitoring. Number 1. OECD Principles on Good Laboratory Practice. Revised. Paris: Organization for Economic Co-operation and Development (OECD); 1997.

20. Yamada M, Welty TE. Generic substitution of antiepileptic drugs: a systematic review of prospective and retrospective studies. Ann Pharmacother. 2011;45(11):1406-1415.

21. Wittayalertpanya S, Chompootaweep S, Thaworn N, Khemsri W, Intanil N. Bioequivalence study of two different formulations of $300 \mathrm{mg}$ gabapentin capsule in Thai healthy volunteers. Thai J Pharm Sci. 2008;32:70-76.

22. Cho HY, Kang HA, Lee YB. Pharmacokinetics and bioequivalence evaluation of two gabapentin preparations after a single oral dose in healthy Korean volunteers. Int J Clin Pharmacol Ther. 2006;44(8): 386-392.
23. Almeida S, Filipe A, Almeida A, et al. Comparative study on the bioequivalence of two different gabapentin formulations. A randomised, two-period, two-sequence, crossover clinical trial in healthy volunteers. Arzneimittelforschung. 2006;56(2):59-63.

24. Yu Y, Teerenstra S, Vanmolkot F, Neef C, Burger D, Maliepaard M. Interchangeability of gabapentin generic formulations in the Netherlands: a comparative bioavailability study. Clin Pharmacol Ther. 2013;94(4): 519-524.

25. Zhu Z, Neirinck L. High-performance liquid chromatographic method for the determination of gabapentin in human plasma. J Chromatogr B Analyt Technol Biomed Life Sci. 2002;779(2):307-312.

26. Gidal BE, Radulovic LL, Kruger S, Rutecki P, Pitterle M, Bockbrader HN. Inter- and intra-subject variability in gabapentin absorption and absolute bioavailability. Epilepsy Res. 2000;40(2-3): 123-127.

27. Sagirli O, Cetin SM, Onal A. Determination of gabapentin in human plasma and urine by high-performance liquid chromatography with UV-vis detection. J Pharm Biomed Anal. 2006;42(5):618-624.

28. Park JH, Jhee OH, Park SH, et al. Validated LC-MS/MS method for quantification of gabapentin in human plasma: application to pharmacokinetic and bioequivalence studies in Korean volunteers. Biomed Chromatogr. 2007;21(8):829-835.

29. Diletti E, Hauschke D, Steinijans VW. Sample size determination for bioequivalence assessment by means of confidence intervals. Int J Clin Pharmacol Ther Toxicol. 1991;29(1):1-8.

\section{Publish your work in this journal}

Drug Design, Development and Therapy is an international, peerreviewed open-access journal that spans the spectrum of drug design and development through to clinical applications. Clinical outcomes, patient safety, and programs for the development and effective, safe, and sustained use of medicines are a feature of the journal, which

\section{Dovepress}

has also been accepted for indexing on PubMed Central. The manuscript management system is completely online and includes a very quick and fair peer-review system, which is all easy to use. Visit http://www.dovepress.com/testimonials.php to read real quotes from published authors.

Submit your manuscript here: http://www.dovepress.com/drug-design-development-and-therapy-journal 